Tropical Journal of Pharmaceutical Research February 2021; 20 (2): 223-230

ISSN: $1596-5996$ (print); 1596-9827 (electronic)

(C) Pharmacotherapy Group, Faculty of Pharmacy, University of Benin, Benin City, 300001 Nigeria.

Available online at http://www.tjpr.org

Original Research Article

http://dx.doi.org/10.4314/tjpr.v20i2.1

\title{
Characterization and biodistribution of trans resveratrol- PEG-folic acid-gold nanoparticle conjugates
}

\author{
Azhoma Gumala, Sutriyo*, Fadlina Chany Saputri \\ Department of Pharmacy, Faculty of Pharmacy, Universitas Indonesia, Depok, Indonesia
}

*For correspondence: Email: sutriyo@farmasi.ui.ac.id; Tel: (+62)8-129 893150

Sent for review: 25 February 2020

Revised accepted: 14 January 2021

\begin{abstract}
Purpose: To evaluate the characteristics and biodistribution of trans resveratrol-PEG-folic acid-gold nanoparticle conjugates (rsv-PEG-FA-AuNP).

Methods: Gold nanoparticles were produced by citric reduction followed by conjugation of PEG-folic acid and resveratrol. Characterization of rsv-PEG-FA-AuNP conjugates including their particle size, zeta potential, and by Fourier transform infrared spectroscopy (FTIR), and transmission electron microscopy (TEM) was carried out. Biodistribution study of rsv-PEG-FA-AuNP was carried out using female Sprague Dawley rats. Biodistribution data were obtained from high performance liquid chromatography (HPLC) analysis.

Results: The mean particle size and zeta potential of rsv-PEG-FA-AuNP were $249.03 \pm 10.31$ and $36.33 \pm 3.12 \mathrm{mV}$, respectively. TEM images showed rsv-PEG-FA-AuNP conjugates formed spherical shape. Rsv-PEG-FA-AuNP conjugates found in plasma, kidney $(1.90 \pm 0.20 \mu \mathrm{g} / \mathrm{g})$, spleen $(2.65 \pm 1.18$ $\mu \mathrm{g} / \mathrm{g})$, liver $(1.74 \pm 0.03 \mu \mathrm{g} / \mathrm{g})$, and lung $(1.82 \pm 0.12 \mu \mathrm{g} / \mathrm{g})$, after 90 minutes intravenous administration (i.v.) in female Sprague Dawley rats. No free resveratrol was found in plasma, kidney, or spleen after i.v administration in female dawdle Sprague Dawley rats.

Conclusion: Resveratrol-PEG-FA-AuNP conjugates appear to be a potential chemotherapy delivery system for active targeting purposes because of its longer systemic circulation and its accumulation in the kidney.
\end{abstract}

Keywords: Gold nanoparticle conjugate, PEGylation, Biodistribution, Folic acid, Folate receptor targeting

This is an Open Access article that uses a fund-ing model which does not charge readers or their institutions for access and distributed under the terms of the Creative Commons Attribution License (http://creativecommons.org/licenses/by/4.0) and the Budapest Open Access Initiative (http://www.budapestopenaccessinitiative.org/read), which permit unrestricted use, distribution, and reproduction in any medium, provided the original work is properly credited.

Tropical Journal of Pharmaceutical Research is indexed by Science Citation Index (SciSearch), Scopus, International Pharmaceutical Abstract, Chemical Abstracts, Embase, Index Copernicus, EBSCO, African Index Medicus, JournalSeek, Journal Citation Reports/Science Edition, Directory of Open Access Journals (DOAJ), African Journal Online, Bioline International, Open-J-Gate and Pharmacy Abstracts

\section{INTRODUCTION}

Gold nanoparticles are a potential device for drug delivery applications, especially in chemotherapy. The cytotoxic drug could be loaded or attached to the nanoparticles so it could target the tumor passively or actively. Because of that, gold nanoparticles were developed for cytotoxic delivery systems with or without ligand [1]. Surface modification of gold nanoparticles with PEG showed improved stability in water and biological fluids [2].

Overexpression of folate receptor had been exploited for active targeting purposes. Folate receptors are highly overexpressed on the 
surface of many types of tumors. Folate receptors also happened to be expressed, to a limited level, in normal cells. Therefore, folate molecules had already been used as targeting moieties in numeral nanotechnology for chemotherapeutic purposes.

Resveratrol, a polyphenol compound, is found in grapes, peanuts, and melinjo [3]. Its potential as an anticancer drug is based on its progressive action as anti-initiation, anti-promotion, and antiprogression of the carcinogen [4]. It has been seen as an anticancer agent in a wide range of human cancers: breast, bladder, blood, bone, brain, cervical, colon, esophageal, eye, gastric, head and neck, kidney, liver, lung, ovarian, prostate, skin, thyroid, uterine I. The natural occurrence and low cost of resveratrol also is a reason that it is promising for further anticancer research [5].

In this study, resveratrol loaded PEG-FA gold nanoparticles were prepared and characterized. Gold nanoparticles were modified with PEG-FA to enhance stability and improve effectiveness for delivery of resveratrol. The resveratrol PEGFA-AuNP conjugates were characterized by particle size, zeta potential, FTIR spectroscopy, morphology, and drug loading. Furthermore, in vitro release and in vivo distribution of the formulation were evaluated using female Sprague Dawley rats. The results were compared with resveratrol in the absence of the nanoparticle vehicle.

\section{EXPERIMENTAL}

\section{Materials}

Trans-resveratrol, HAuCl4, PEG-bis-amine, folic acid, N-(3-dimethylaminopropyl)-N`-ethylcarbodiimide (EDC), N-hydroxysuccinimide (NHS) were purchased from Sigma Aldrich (St. Louis, MO, USA). Carolina dialysis tubes 12,000-14,000 daltons was purchased from Carolina Biological Supply (North Carolina, USA). High performance liquid chromatography (HPLC)-grade methanol was purchased from Merck Millipore (St. Louis, MO, USA). Acetic acid, chloride acid, and dimethyl sulfoxide were analytical grade.

\section{Animals}

Female adult Sprague-Dawley rats (135 g-180 g; $n=6)$ were housed in cages ( $n=3 /$ cages) under controlled conditions of 12 hours light and 12 hours dark and a temperature of $26 \pm 3^{\circ} \mathrm{C}$ and relative humidity. They received a standard diet and water ad libitum. The animals were acclimated for one week before being treated.
Handling and killing of rats were approved by The Ethics Committee of the Faculty of Medicine, University of Indonesia (No. 0934/UN2.F1/ETIK/2018) in accordance with NIH principles of laboratory animal care [6]. All animal manipulations were carried out in the morning to minimize circadian rhythm

\section{Preparation of gold nanoparticles}

Gold nanoparticles were prepared by citric reduction. $\mathrm{HAuCl}_{4} 10 \mathrm{ml}$ was stirred and heated to a temperature of $100 \pm 5{ }^{\circ} \mathrm{C}$, and $0.282 \mathrm{ml}$ of natrium citrate $130 \mathrm{mM}$ was added to the solution. Stirring continued until the color of the solution changed from pale yellow to transparent to red.

\section{PEG-FA activation}

NHS $300 \mathrm{mg}$ and EDC $100 \mathrm{mg}$ were added to $25.03 \mathrm{mg}$ folic acid in $0.5 \mathrm{ml} \mathrm{HCl}$ and $0.5 \mathrm{ml}$ DMSO then stirred for 6 hours. PEG bis-amine $250 \mathrm{mg}$ was added and the solution was mixed for another 6 hours.

\section{Conjugation of resveratrol-PEG-folic acid-gold nanoparticle}

Resveratrol $10 \mathrm{mg}$ and gold nanoparticles $10 \mathrm{~mL}$ were added to the PEG-FA compound. The final formulation was centrifuged at $1500 \mathrm{rpm}$ for 30 minutes. Sediment was collected and stored at a cool temperature $\left(10 \pm 5^{\circ} \mathrm{C}\right)$.

\section{Characterization of resveratrol-PEG-folic acid-gold nanoparticle conjugates}

\section{Particle size, distribution analysis, and zeta potential analysis}

Particle size and zeta potential were measured by dynamic light scattering at $25^{\circ} \mathrm{C}$ using Horiba SZ-100 (Kyoto, Japan). The polydispersity index (PDI) was measured as size distribution value. Distilled water added to Rsv-PEG-FA-AuNP (conductivity $0.399 \mathrm{mS}$, viscosity $0.896 \mathrm{mPa}$ ) before analysis. The zeta potential was assessed by determining the particle electrophoretic mobility using Horiba SZ-100. The measurements were performed in triplicate.

\section{Ultraviolet-visible spectroscopy analysis}

The UV spectroscopy spectrum of rsv-PEG-FAAuNP and the spectra of individual components were compared. The conjugate was pipetted \pm $100 \mu \mathrm{l}$ and dispersed in water. The spectra of this compound were recorded by JASCO V530. 
Resveratrol and gold nanoparticles underwent the same procedure.

\section{Fourier transform infrared spectroscopy}

Samples were mixed with $\mathrm{KBr}$ and the spectra were recorded using Shimadzu FTIR 840 OS. $\mathrm{KBr}$ also was recorded as the background of analysis.

\section{Transmission electron microscopy}

The structure and morphology of gold nanoparticle and gold nanoparticle conjugate were observed with transmission electron microscopy using Tecnai G2 Spirit Twin microscope.

\section{Drug loading}

Drug loading is defined as the percentage of resveratrol incorporated into the conjugate compared to the total resveratrol added. Standard solutions of resveratrol diluted in methanol were prepared in 7 concentrations: 1 $\mu \mathrm{g} / \mathrm{ml}, 2.5 \mu \mathrm{g} / \mathrm{ml}, 5 \mu \mathrm{g} / \mathrm{ml}, 7.5 \mu \mathrm{g} / \mathrm{ml}, 10 \mu \mathrm{g} / \mathrm{ml}$, $12.5 \mu \mathrm{g} / \mathrm{ml}, 15 \mu \mathrm{g} / \mathrm{ml}$ to plot a calibration curve. The amount of resveratrol in the conjugates was determined using HPLC

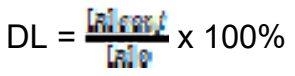

where: $\mathrm{DL}$ = drug loading; $[\mathrm{R}]$ conj = calculated resveratrol measured in formula; $[R] 0=$ resveratrol added during production.

\section{In vitro release study}

$X 100 \% A n$ in vitro release study was conducted using a dialysis tube 12,000-14,000 daltons. RsvPEG-FA-AuNP conjugates placed $2 \mathrm{ml}$ in the cut off dialysis tube. The tubes were placed in a glass beaker containing $20 \mathrm{ml}$ of medium: HCL $\mathrm{pH} 2$ and phosphate buffer $\mathrm{pH}$ 7.4. The medium collected $1 \mathrm{ml}$ for at $0,5,15,60,120,180$, and 360 minutes and rapidly replaced to maintain 20 $\mathrm{ml}$ volume. The samples were measured using an UV spectrometer, Jasco V530. Absorbance of the samples that were converted into the resveratrol concentration was determined using a linear plot equation.

\section{Biodistribution studies}

\section{Sample preparation}

Excised tissues were perfused by $\mathrm{NaCL} 0.9 \%$, wiped by filter paper, weighed, and minced. Acetic acid glacial $(2.5 \% \mathrm{v} / \mathrm{v})$ and $10 \mu \mathrm{l}$ ascorbic acid (15\% b/v) as an antioxidant were added to the tissues and they were homogenized using a glass mortar and pestle. The homogenized samples were placed in a glass tube $(3 \mathrm{ml})$ and centrifuged at $3000 \mathrm{rpm}$ for 30 minutes. The supernatant was collected, passed through a $0.45 \mu \mathrm{m}$ filter, and analyzed. Blood obtained from the aorta was placed in an NaEDTA tube and centrifuged to collect a plasma sample. Plasma samples were pipetted at $0.5 \mathrm{ml}$, and methanol $80 \%$ acidified with acetic acid $2.5 \%$ was added. The liquid was then shaken and passed through a $0.45 \mu \mathrm{m}$ filter for further analysis.

\section{Method validation}

A validation assay was carried out by spiking the tissues with $10 \mu \mathrm{g} / \mathrm{g}$ resveratrol. Precision and accuracy were measured in 6 samples of liver tissue and 56 samples from 5 other tissues (brain, kidney, liver, lung, spleen). Precision was expressed as the relative standard deviation (\%RSD). Accuracy was estimated as the mean percentage of error from the measured concentration to theoretical concentration as in Eq 2.

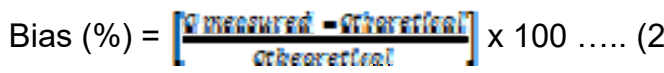

Peak plasma ratio of extracted spiked sample and corresponding concentration were calculated to measured recoveries. Linearity and sensitivity were determined using 7 progressive concentrations $(0.5,1,5,7.5,10,15$, and 25 $\mu \mathrm{g} / \mathrm{g}$ ) of spiking resveratrol extracted from liver tissue homogenates. Peak areas versus analyte concentrations were then plotted to constructed calibration curve. The linear regression formula, correlation coefficient, LOD, and LOQ were calculated from the calibration curve. The LOD was formulated as 3 times the standard deviation of the low concentration per slope, and LOQ was formulated as 10 times the standard deviation of low concentration per slope.

\section{Biodistribution study}

Free resveratrol and the PEG-FA gold nanoparticle conjugation formula were administered intravenously in a single dose of 2 $\mathrm{mg} / \mathrm{kg}$ into two groups of 3 rats each. The animals were sacrificed $90 \mathrm{~min}$ after injection. Blood from the aorta, brain, liver, kidney, lungs, and spleen were rapidly collected. Blood was placed in Na-EDTA tube and centrifuged to collect plasma, while the organs were perfused with $\mathrm{NaCl} 0.9 \%$, wiped with filter paper and weighed. The tissues were extracted with $2 \mathrm{ml}$ of methanol $80 \%$ acidified with acetic acid $2.5 \%$ and homogenized 7]. The homogenized samples 
were centrifuged at $3000 \mathrm{rpm}$ for 30 minutes. The supernatant was collected, passed through a $0.45 \mu \mathrm{m}$ filter, and analyzed at $306 \mathrm{~nm}$ using a C18 analytical column (Inertsil ODS-3; $5 \mu \mathrm{m} x$ $4.6 \mathrm{mmx} 250 \mathrm{~mm}$ ). The instruments used were a Shimadzu model LC-20AT pump and an SPD $10 A$ UV Vis detector. Isocratic delivery of methanol: water (1: 1) was used as a mobile phase at a flow rate of $1 \mathrm{ml} / \mathrm{min}$.

\section{Statistical analysis}

Results of the biodistribution study were analyzed by independent two sample $t$ test $(\alpha=$ 0.05) using SPSS software.

\section{RESULTS}

\section{Characteristics of resveratrol-PEG folic acid gold nanoparticle conjugates}

The color of the rsv-PEG-FA-AuNP conjugates was violet blue. The particle size, polydispersity index, and zeta potential of both the gold nanoparticle and the formulation are shown in Table 1.

UV-Vis spectroscopic analyses were conducted to record the wavelength of maximum absorption of the conjugates to identify the compound compared to its individual components. The UV Vis spectra of rsv-PEG-FA-AuNP presented the maximum absorption in both the resveratrol wavelength $(306 \mathrm{~nm})$ and the gold nanoparticle wavelength $(533.5 \mathrm{~nm})$. The results are shown in Table 2.

Fourier transform infrared spectroscopy (FTIR) was conducted to determine whether there was any interaction between resveratrol, PEG bisamine, and folic acid in the formulation of conjugates. The results are shown in Figure 1.

Resveratrol showed an absorption band of $\mathrm{C}-\mathrm{O}$ stretching at $1100-1500 \mathrm{~cm}^{-1}, \mathrm{C} \mathrm{C}$ stretching of aromatic ring $1400-1600 \mathrm{~cm}^{-1}, \mathrm{O}-\mathrm{H}$ stretching of an alcoholic group at $3000-3500 \mathrm{~cm}^{-1}, \mathrm{C}-\mathrm{C}$ stretching at $1500-1700 \mathrm{~cm}^{1}$.

Table 2: Wavelength of maximum absorption from rsvPEG-FA-AuNP conjugates, gold nanoparticles, and resveratrol

\begin{tabular}{|c|c|c|c|}
\hline Compound & $\lambda_{(\mathrm{nm})}^{\max }$ & AuNP & $\begin{array}{l}\lambda \quad \max \\
\operatorname{Rsv}(\mathrm{nm})\end{array}$ \\
\hline \multirow{2}{*}{$\begin{array}{l}\text { Gold } \\
\text { nanoparticles }\end{array}$} & \multicolumn{2}{|c|}{533.5} & - \\
\hline & \multicolumn{2}{|l|}{-} & 306 \\
\hline $\begin{array}{l}\text { Rsv-PEG-FA- } \\
\text { AuNP }\end{array}$ & \multicolumn{2}{|l|}{534} & 306 \\
\hline
\end{tabular}

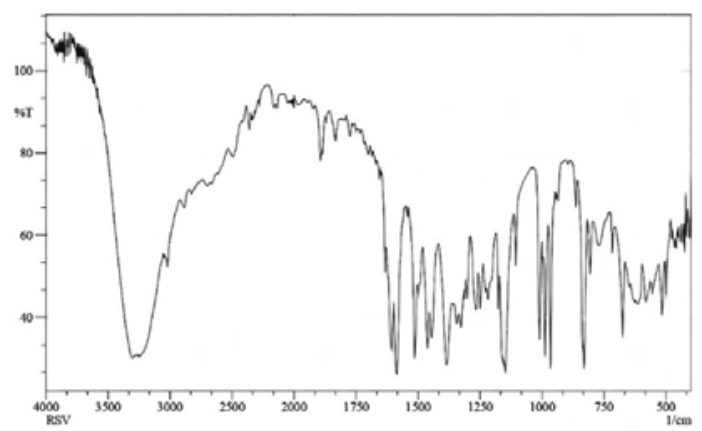

(A)

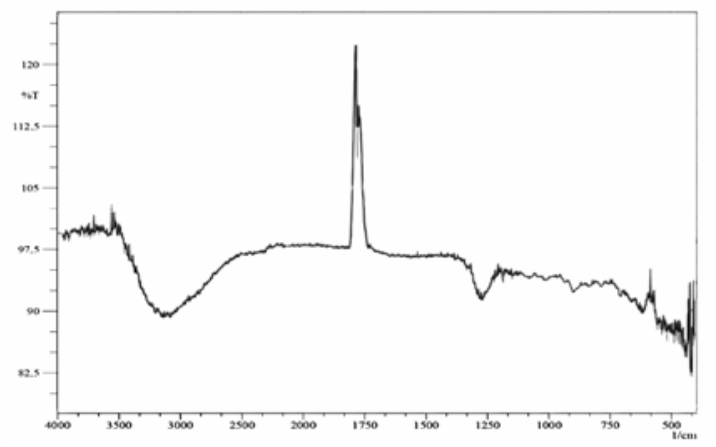

(B)

Figure 1: FTIR spectrum of, resveratrol (A) and FTIR spectrum of rsv-PEG-FA-AuNP(B)

Table 1: Particle size, polydispersity index, zeta potential and drug loading of AuNP and rsv-PEG-FA-AuNP conjugates $(n=3)$

\begin{tabular}{lcc}
\hline Parameter & AuNP & $\begin{array}{c}\text { Rsv-PEG-FA-AuNP } \\
\text { conjugates }\end{array}$ \\
\hline Color & Red & Violet \\
Particle size $(\mathrm{nm})$ & $57.40 \pm 1.05$ & $249.03 \pm 10.31$ \\
Polydispersity index (PDI) & $0.246 \pm 0.047$ & $0.915 \pm 0.089$ \\
Zeta potential (mv) & $-6.4 \pm 9.90$ & $-36.33 \pm 3.12$ \\
Drug loading $(\%)^{*}$ & - & 60 \\
\hline
\end{tabular}

*Drug loading of resveratrol in rsv-PEG-FA-AuNP was calculated using linear regression equation $y=147432 x+$ $15543(r=0.999)$ 
PEG bis-amine and PEG-FA showed absorption band of $\mathrm{O}-\mathrm{H}$ stretching of aliphatic chain in $3333 \mathrm{~cm}^{1}$, and $\mathrm{N}-\mathrm{H}$ stretching at $3300-3500 \mathrm{~cm}^{1}$. Rsv-PEG-FA-AuNP conjugates showed absorption bands of $\mathrm{O}-\mathrm{H}$ and $\mathrm{N}-\mathrm{H}$ stretching at $3000-3500 \mathrm{~cm}^{1}$. Rsv-PEG-FA-AuNP conjugates also showed absorption bands from $\mathrm{C}=\mathrm{O}$ and $\mathrm{C}$ $=\mathrm{N}$ stretching at $1600-1700 \mathrm{~cm}^{1}$.

TEM analysis revealed spherical shapes of rsvPEG-FA-AuNP conjugate (Figure 2).

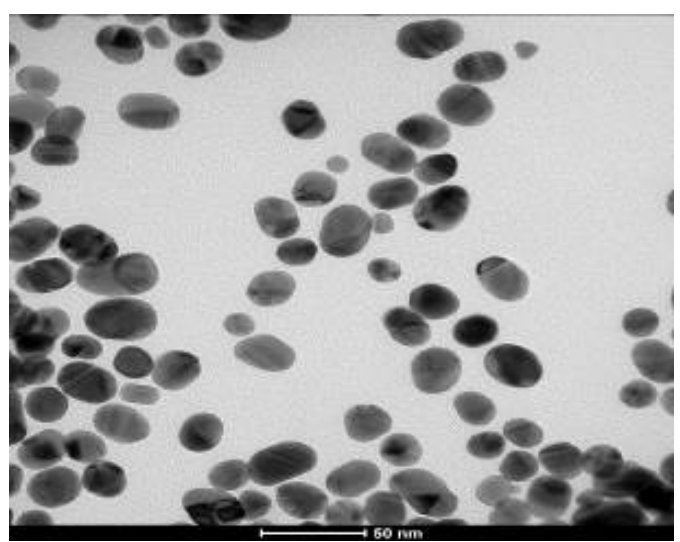

Figure 2: Image of rsv-PEG-FA-AuNP from a transmission electron microscope (TEM)

\section{In vitro release}

Absorbance of samples was converted into the resveratrol concentration using linear plot equation $y=0.3313 x+0.1225$. The concentration was multiplied by the volume of medium and a correction factor was applied to plot the amounts of resveratrol released versus time in two different $\mathrm{pH}$ levels (Figure 3).

\section{Biodistribution}

\section{Validation}

The chromatograms of blank plasma, spiked plasma, and plasma taken 90 min after intravenous injection showed peak area at UV wavelength $306 \mathrm{~nm}$ with a retention time of 10 minutes using HPLC condition as described, while the peak did not present in the blank samples. Peak areas of resveratrol were detected at UV wavelength $306 \mathrm{~nm}$ with a retention time of 10 minutes using HPLC conditions as described, while the peak did not present in the blank sample.

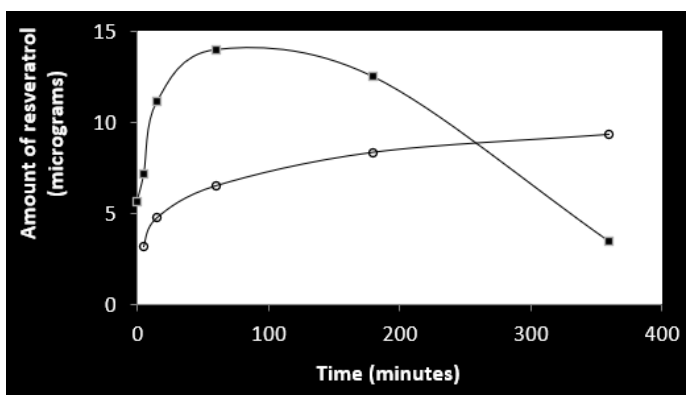

Figure 3: Resveratrol released in $\mathrm{HCl}\left(*-\mathrm{pH}^{2}\right)$ and phosphate buffer $(\rightarrow$ pH 7.4$)$ media

To measure the recovery of resveratrol in plasma and organs, the peak areas of the samples and controls with similar concentrations were compared. The highest peak area of spiked resveratrol in plasma was the closest value to positive control. The height peak area of spiked resveratrol in several organs were less than half of the positive control. The data for recovery, precision, and accuracy of the analytical procedure are shown in Table 3.

The precision of the methods was lower than $20 \%$, and the percent of bias for the accuracy of the methods was lower than the $15 \%$ limit. Both parameters were within the limit of acceptance. The recovery of extraction from homogenates ranged from $33 \%$ to $40 \%$ (liver and spleen both had $33 \%$ recovery, kidney had $34 \%$, and brain and lung had $40 \%$, with the RSD lower than $2 \%$ for $n=2$ each tissue), while the recovery from plasma was $70 \%$. Linear calibration curves were plotted over $0.5 \mu \mathrm{g} / \mathrm{g}-25 \mu \mathrm{g} / \mathrm{g}$ tissues in homogenized liver tissues. The equation for the linear plot was $\mathrm{y}=10981 \mathrm{x}-6237 \mathrm{y}=10981 \mathrm{x}$ 6237 , with a correlation coefficient 0.999 . The average limit of detection and limit of quantification were $0.035 \mathrm{pg}$ and $0.1 \mathrm{pg}$, respectively.

Table 3: Accuracy, precision, and recovery of resveratrol from spiked homogenates

\begin{tabular}{|c|c|c|c|c|}
\hline \multirow[t]{2}{*}{ Tissue } & \multirow{2}{*}{$\begin{array}{l}\text { Accuracy } \\
\text { (Bias, \%) }\end{array}$} & \multicolumn{2}{|c|}{ Precision } & \multirow{2}{*}{$\begin{array}{c}\text { Recovery } \\
\text { (\%) }\end{array}$} \\
\hline & & Intra day & Inter day & \\
\hline Liver $(n=6)$ & $1 \%$ & 3.10 & $\mathrm{~N} / \mathrm{A}$ & $33 \pm 1$ \\
\hline Internal organ $(n=5)$ & $10 \%$ & 8.39 & 11.02 & $36.2 \pm 3.9$ \\
\hline
\end{tabular}


The biodistribution of the conjugates and resveratrol in Sprague Dawley rats (2 groups, $n=$ 3) was determined using previously validated methods. The results are shown in Table 4. The amount of resveratrol deposit in organs 90 min after i.v. injection was calculated using the linear regression value $y=10981 x-6237$. The $x$ represented the amount of resveratrol detected and $y$ was the peak areas from HPLC measurements (RT $10 \pm 1 \mathrm{~min}$ ). Concerning the intake of free resveratrol, resveratrol was not detected in plasma and the spleen. In the liver and lung, resveratrol in its free form was detected in only one sample and not the other two. Resveratrol in the conjugated form, rsvPEG-FA-AuNP, was detected widely in several organs: spleen, brain, liver, and lung 90 minutes after i.v. injection (Figure 7). The amount of rsvPEG-FA-AuNP in plasma was calculated from peak area using a similar linear regression, multiplied by (3/7). The value $3 / 7$ was based on the level of resveratrol recovery from plasma compared to recovery from liver. By applying this calculation, the concentration values of resveratrol in the conjugated form, rsv-PEG-FAAuNP, was $0.83 \pm 0.02 \mu \mathrm{g} / \mathrm{mL}(\mathrm{n}=3)$.

Table 4: Amount of resveratrol detected in the plasma and several organs of rates $90 \mathrm{~min}$ after i.v. delivery

\begin{tabular}{lcc}
\hline $\begin{array}{l}\text { Organ } \\
(\mathbf{n}=\mathbf{3})\end{array}$ & $\begin{array}{c}\text { Rsv-PEG-FA- } \\
\text { AuNP }(\boldsymbol{\mu g} / \mathbf{g})\end{array}$ & Rsv $(\boldsymbol{\mu g} / \mathbf{g})$ \\
\hline Spleen & $2.65 \pm 1.18$ & 0 \\
Brain & $1.89 \pm 0.08$ & $1.89 \pm 0.39$ \\
Kidney & $1.90 \pm 0.20$ & 0 \\
Liver & $1.74 \pm 0.03$ & $0.58 \pm 1.00$ \\
Lung & $1.82 \pm 0.12$ & $0.62 \pm 1.07$ \\
\hline
\end{tabular}

Statistical analysis of the biodistribution of rsvPEG-FA-AuNP showed differences from the biodistribution of resveratrol in plasma, spleen, and kidney that were significant. The $p$-values were $.0001, .003$, and .0001 , respectively. The $p-$ values for the biodistribution in the brain, liver, and lung were .493, .091, and .096. That means there was no significant difference from rsv-PEGFA-AuNP and resveratrol.

\section{DISCUSSION}

Gold nanoparticles were synthesized by citric reduction of tetrachloroauric acid with reduction agent as conducted by Turkevich [8]. The gold nanoparticles were then conjugated to folic acid via PEG terminal amino group while also loaded with resveratrol (Figure 5). Esterification of folic acid with $\mathrm{N}$-hydroxysuccinimide (NHS) in the presence of DCC had already been developed by Stella et al [9].
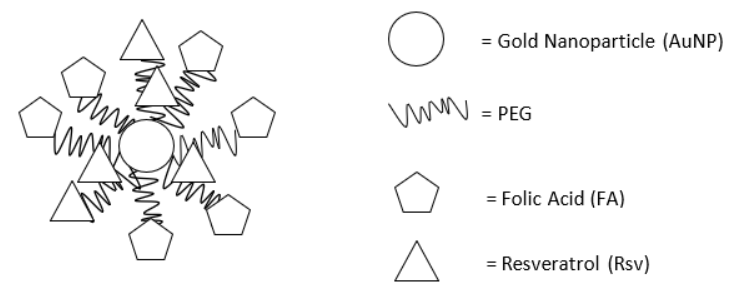

Figure 5. Schematic of rsv-PEG-FA-AuNP conjugates

The rsv-PEG-FA-AuNP conjugates increased in size and polydispersity index almost five times as much as gold nanoparticles (Table 1). The larger particle size could be due to an increase of particle agglomeration as the gold nanoparticle attached to PEG-FA while also adding resveratrol. The larger particle size and the polymer chain could be the reason for the increasing dispersity index. Moreover, it is notable that the polydispersity in chain length grafted in flat surfaces could alter chain conformations and the overall height of the grafted layer on the surface. This would vary the polydispersity index [10]. However, rsv-PEG-FAAuNP showed improvement in colloidal systems stability (Table 1). The system had a zeta potential value greater than $\pm 30 \mathrm{mV}$. This result was considered stable formulation as colloidal dispersion., rsv-PEG-FA-AuNP conjugates had a more enhanced dispersion stability in water than gold nanoparticles.

The FTIR spectrum confirmed the possibilities of the rsv-PEG-FA-AuNP conjugates, and there was no interference between individual components. absorption bands of resveratrol, PEG, FA, and rsv-PEG-FA-AUNP were attributed according to literature [11].

The TEM analysis could provide information only about the metallic core of rsv-PEG-FA-AuNP conjugates without the exterior layer of gold surface. Using PEG to coat gold nanoparticles did not change the dimension of the metallic core. The greater surface of the enlarged molecules contributed to the difference in size of the gold nanoparticle products [12].

The in vitro release study in $\mathrm{HCl} \mathrm{pH} 2$ and phosphate buffer $\mathrm{pH} 7.4$ showed that resveratrol from rsv-PEG-FA-AuNP conjugates was released at a more measured manner in $\mathrm{pH} 2$, whereas the amount of resveratrol in $\mathrm{pH} 7.4$ decreased after 60 minutes while the amount continued increased in the lower pH (Figure 3). Resveratrol stability is known to be strongly 
influenced by $\mathrm{pH}$. In acidic $\mathrm{pH}$, trans resveratrol was more stable than in a medium $\mathrm{pH}$ above 6.8. This result suggested that rsv-PEG-FA-AuNP was more stable in acidic $\mathrm{pH}$, ensuring its controlled release into an acidic environment [13].

The biodistribution study of resveratrol used liquid precipitation followed by chromatographic analysis using HPLC at $306 \mathrm{~nm}$. The method was introduced in the quantification analyses of Juan et al and Huan et al $[7,14]$. Validation of the methods showed results that were acceptable according to FDA guidelines, with accuracy and precision less than $15 \%$. In the biodistribution study of free trans-resveratrol, the highest concentration was found in the brain while none was detected in the spleen and kidney. Menet et al reported that 30 minutes after oral intake of resveratrol in mice, a greater amount of trans resveratrol was found in the brain, followed by plasma and heart tissue [15]. Juan et al. reported that the concentration of resveratrol was highest in the kidneys of male rats and lowest in the brain 90 min after i.v. injection. It is worth noticing that in this study, the amount of resveratrol from rsv-PEG-FA-AuNP conjugates found in the brain was similar to the amount of free resveratrol, while there was more resveratrol from the conjugates in the spleen, kidney, liver, and lung than there was free resveratrol. The amount of resveratrol in the brain could be restricted by its particle size. Resveratrol from rsv-PEG-FA-AuNP conjugates also appeared to stay longer in systemic circulation while no free resveratrol was detected in rat plasma 90 minutes after i.v. injection in the tail vein. The results are similar to those of De Jong et al, who showed that gold nanoparticles that were $10 \mathrm{~nm}$ in size were the most widespread, while larger particles were mostly confined to the blood, spleen, and liver. The higher amount of resveratrol from rsv-PEGFA-AuNP conjugates in plasma could result from PEGylation [16]. PEGylation was proved to prolong circulation time because its shield function protected nanoparticles from aggregation, opsonization, and phagocytosis [17].

The localization of rsv-PEG-FA-AuNP in the spleen may be due to phagocytosis by mononuclear phagocytes systems. Resveratrol from rsv-PEG-FA-AuNP conjugates found in the kidney are suitable because of the expression of folate receptors on the luminal side of the brush border membrane in proximal tubule cells. Folate receptors facilitated reabsorption of folate from urine, preventing its loss from the body. In normal organs and tissue, folate receptors are expressed at the epithelium $n$ placenta, kidney and plexus choroid [18]. The expression of folate receptors in plexus choroid could also contribute to the amount of rsv-PEG-FA-AuNP in the brain. However, this theory needs further investigation. It is also worth noting that higher resveratrol in the form of rsv-PEG-FA-AuNP in the kidney could contribute to its further elimination, as the kidney appears to be its preferred organ of excretion, whereas the small amount of resveratrol detected from its free intake could be because of its rapid metabolism.

\section{CONCLUSION}

Gold nanoparticles modified by PEG and folic acid conjugates are potentially suitable drug carriers for resveratrol, a potential chemotherapy substance. However, the methods for purifying the conjugate should be developed further to achieve better particle distribution. Rsv-PEG-FAAuNP conjugates appeared larger in size than AuNP, and they were stabilized by PEG. Those properties would restrict its distribution to certain organs while prolonging its systemic circulation. It showedthat rsv-PEG-FA-AuNP stayed in systemic circulation longer, its localization in kidney was due to the expression of folate receptors in that organ.

\section{DECLARATIONS}

\section{Acknowledgement}

The authors acknowledge the Integrated Laboratory Research Center, Universitas Indonesia, for technical support. PITTA funding is also acknowledged (no. 1781/UN2.R3.1/HKP.05.00/2018) for providing grants for this research.

\section{Conflict of interest}

There is no conflict of interest associated with this work.

\section{Contributions of the authors}

We declare that this work was done by the author(s) named in this article and all liabilities pertaining to claims relating to the content of this article will be borne by the authors. This study was conceived and designed by Azhoma Gumala, Sutriyo, and Fadlina Chany Saputri. The data were collected by Azhoma Gumala. The data analysis was done by Azhoma Gumala, Sutriyo, and Fadlina Chany Saputri. The article was written by Azhoma Gumala with reviews and corrections from Sutriyo and Fadlina Chany Saputri.

Trop J Pharm Res, February 2021; 20(2): 229 


\section{Open Access}

This is an Open Access article that uses a funding model which does not charge readers or their institutions for access and distributed under the terms of the Creative Commons Attribution License (http://creativecommons.org/licenses/by/ 4.0) and the Budapest Open Access Initiative (http://www.budapestopenaccessinitiative.org/rea d), which permit unrestricted use, distribution, and reproduction in any medium, provided the original work is properly credited.

\section{REFERENCES}

1. Sing P, Pandit S, Mokkapati VRSS, Garg A, Ravikumar $V$, Ivan $M$. Gold nanoparticles in diagnostic and therapeutics for human cancer. Int J Mol Sci 2018; 19(7): 1979.

2. Rahme K, Nolan MT, Doody T, Glacken GP, Morris MA, O'Driscoll C, Holmes JD. Highly stable PEGylated gold nanoparticles in water: Applications in biology and catalysis. RSC Adv 2013; 3: 21016-21024.

3. Ahmad I, Andriyani D, Gunawan C, Fauziah ND, Sutriyo $S$, Mun'im A. Effects of food processing on resveratrol and total phenolic content in melinjo (Gnetum gnemon L.) seeds. Phcog J 2018; 10(60): 1096-1100.

4. Jang M, Cai L, Udeani GO, Slowing KV, Thomas CF, Beecher CW, Fong $H H$, Farnsworth NR, Kinghorn $A D$, Mehta RG, Moon RC, Pezzuto. Cancer chemopreventive activity of resveratrol, a natural product derived from grapes. Science 1997; 275(5297): 218-220.

5. Rauf A, Imran $M$, Butt MS, Nadeem M, Peters DG, Mubarak MS. Resveratrol as an anti-cancer agent: $A$ review. Crit Rev Food Sci Nutr 2018; 58(9): 1428-1447.

6. National Research Council (US) Committee for the Update of the Guide for the Care and Use of Laboratory Animals. Guide for the Care and Use of Laboratory Animals. 8th ed. Washington (DC): National Academies Press (US); 2011. PMID: 21595115.7. Juan ME, Maijó
M, Planas JM. Quantification of trans-resveratrol and its metabolites in rat plasma and tissues by HPLC. J Pharm Biomed Anal 2010; 51(2): 391-398.

7. Turkevich J, Stevenson P, Hillier J. A study of the nucleation and growth process in the synthesis of colloidal gold. Discuss Faraday Soc 1951; 11: 55.

8. Stella B, Arpico S, Peracchia MT, Desmaele D, Hoebeke J, Renoir M, D’Angelo JD, Catttel L, Couvreur P. Design of folic acid-conjugated nanoparticles for drug targeting. J Pharm Sci 2008; 9(11): 1452-1464.

9. Martin TB, Dodd PM, Jayaraman A. Polydispersity for tuning the potential of mean force between polymer grafted nanoparticles in a polymer matrix. Phys 2013; 110(1): 018301.

10. Schrader B. Organic substances. In Schrader B, editor. Infrared and Raman spectroscopy: methods and applications. Weinheini: VCH publishers. Inc; 1995.

11. Mioc M, Pavel IZ, Ghiulai R, Coricovac DE, Farcaş C, Mihali CV, Şoica, C. The cytotoxic effects of betulinconjugated gold nanoparticles as stable formulations in normal and melanoma cells. Front Pharmacol 2018; 9: 429.

12. Zupančič Š, Lavric Z, Kristi J. Stability and solubility of trans-resveratrol are strongly influenced by $\mathrm{pH}$ and temperature. Eur J Pharm Biopharm 2015; 93: 196-204.

13. Juan ME, Rosa ML, Carmen TB, Joana MP. Determination of trans-resveratrol in plasma by HPLC. Anal. Chem 1999; 71(3); 747-750.

14. Menet MC, Baron S, Taghi M, Diestra R, Dargere D, Laprevote O, Nivet-Antoine V, Beaudeux JL, Bedarida $T$, Cottart $\mathrm{CH}$. Distribution of trans-resveratrol and its metabolites after acute or sustained administration in mouse heart, brain, and liver. Mol Nutr Food Res 2017; 61(8).

15. Suk JS, Xu Q, Kim N, Hanes J, Ensig LM. PEGylation as a strategy for improving nanoparticle-based drug and gene delivery. Adv Drug Deliv Rev 2016; 99(Pt A): 2851.

16. Weitman $S D$, Weinberg AG, Coney LR, Zurawski VR, Jennings DS, Kamen BA. Cellular localization of the folate receptor: potential role in drug toxicity and folate homeostasis. Cancer Res 1992; 52: 6708-6711. 